\title{
La abolición de los derechos y prestaciones señoriales: La Ley de Reforma Agraria y su interés para la Historia Medieval y Moderna
}

\author{
JOSÉ-LuIS MARTÍN \\ AMANDA CABO \\ Maria pia Senent \\ DOLORES MORENO dE VEGA
}

Poco y mal conocidos, los archivos de la Reforma Agraria 'son básicos para el conocimiento de nuestra historia contemporánea y, en algunos casos, interesantes y de consulta obligada para los estudiosos de la Edad Media y de la Época Moderna, no sólo porque la documentación reunida "arrastra» textos probatorios de derechos anteriores que a veces se remontan a los tiempos medievales, sino también porque entre los objetivos de la Reforma Agraria ocupa un lugar destacado la supresión de algunas pervivencias medieval-modernas, la abolición de las prestaciones y derechos señoriales, a las que se refieren de modo expreso la Ley del 15 de septiembre de 1932, la Orden del 10 de marzo de 1933 y el Decreto del 24 de noviembre del mismo año, que desarrolla la base 22 de la Ley de Reforma Agraria y fija las normas para determinar, “en cada caso, el

\footnotetext{
En el mejor de los casos se han utilizado los fondos archivisticos del Instituto de Reforma Agraria relativos a los lugares donde realmente se aplicó o se intentó aplicar la reforma (Andalucia, Extremadura, Salamanca y Toledo) olvidando la documentación reunida desde el año 1907 por la Junta de Colonización y Repoblación Interior, prescindiendo de los miles de documentos (encuestas, relaciones de bienes comunales, montes cultivables, censos de campesinos...) previos a la Reforma, e ignorando incluso la existencia de los miles de documentos reunidos tras el triunto de los antirreformistas por el Servicio de Reforma Económica y Social de la Tierra, por el Servicio de Recuperación Agrícola o, desde el 18 de octubre de 1939, por el Instituto Nacional de Colonización, documentos que se conservan en el instituto Nacional de Reforma y Desarrollo Agrario (IRYDA) que prepara en estos momentos la edición de un inventario de las cerca de dos mil cajas conservadas.
} 
carácter señorial de las prestaciones que quedan abolidas, a fin de que los que fueron pagadores puedan proveerse de un título declarativo de la inexistencia del gravamen, con el cual se lleve a cabo la cancelación de las inscripciones o menciones de dichos gravámenes en el Registro de la Propiedad" ?

Junto a normas administrativas que dejan en manos del Instituto de Reforma Agraria ("contra sus acuerdos no se dará recurso alguno") la decisión sobre el carácter señorial de las prestaciones y fijan el procedimiento para incoar y dar curso al expediente, el Decreto, en sus artículos 2 a 4, intenta definir las prestaciones señoriales:

Art. 2. Para determinar el carácter señorial de una prestación se atenderá exclusivamente al origen de la misma, sin que pueda considerarse en ningún caso convalidada por la prescripción, ni por transformaciones, de su carácter jurídico dimanantes de concordias, laudos o sentencias, ni por el título oneroso o gratuito mediante el que fueron adquiridas por el perceptor o sus causantes.

Art. 2. Se presumirá siempre que las prestaciones provienen de derechos señoriales:

1. Cuando asi resulte del título de señorio o cuando hayan sido originariamente constituidas a favor de las personas que en la fecha de la constitución tuvieran jurisdicción sobre los territorios o pueblos en que recaigan, aunque hayan sido transformadas después o declaradas de carácter civil por concordias, laudos, sentencias, anteriores o posteriores a 6 de agosto de $1811^{3}$.

2. Cuando tenga su origen en contratos celebrados con posterioridad al 6 de agosto de 1811, entre los pagadores y los que por sí o por sus causantes hayan ejercido jurisdicción sobre los territorios o pueblos siempre que estos contratos traigan causa de pleito pendiente o ya fallado, entre aquéllos y éstos.

3. Cuando los pagadores sean pueblos y el reparto de la prestación se haga entre sus vecinos.

4. Cuando no recaigan sobre fincas especificamente determinadas.

E| Decreto fue publicado en la Gaceta del 26 de noviembre de 1933.

${ }^{3}$ La aclaración de que el origen de la prestación basta para anularla a pesar de posibles acuerdos entre las partes pretende, sin duda, evitar que se legitimen, como ha hecho en diversos casos el Tribunal Supremo, prestaciones señoriales abolidas en principio desde el 6 de agosto de 1811 y «reestablecidas» en fallos de 1864, 65, 68 y 82 en los que se decidió "que si con posterioridad a aquel Decreto las prestaciones por èl abolidas habian sido objeto de transacción o contrato, subsistian con toda fuerza de obligar", según recuerda en 1936 el abogado de los beneficiarios de un censo en el pueblo segoviano de Madriguera en un pleito sobre el que habremos de volver más adelante. 
Si interpretamos bien el sentir de los reformistas, se entiende que tienen carácter señorial los derechos económicos con origen en la autoridad ejercida por los beneficiarios en el momento de crearse la prestación o, dicho de otro modo, en el abuso de los señores que no conformes con percibir las rentas de sus tierras, exigen a quienes dependen de ellos pagos colectivos injustificados, que no recaen sobre fincas concretas y por tanto no pueden ser rentas o censos por la utilización de la tierra.

Con estas normas, se abre una puerta para resolver los litigios antiguos y los que puedan plantearse nuevamente, al margen de los tribunales ordinarios, y por ella entrarán numerosos municipios de toda España que, con razón o sin ella, se consideraban sometidos al pago de prestaciones y derechos señoriales e intentarán conseguir su abolición y el oportuno documento acreditativo. La iniciativa parte de los afectados pero, en ocasiones, son los Gobiernos Civiles los que impulsan y promueven las reclamaciones y exigen a los alcaldes que envien relaciones de las fincas comunales, baldias y de señorio ${ }^{4}$ existentes en cada término municipal o, caso menos frecuente, crean un gabinete de investigación para colaborar con los municipios.

Entre los numerosos ejemplos que podriamos citar, hemos seleccionado el de Segovia, provincia para la que se conservan cuatro cajas relativas a este aspecto de la Reforma Agraria, con las peticiones elevadas por los municipios y por particulares, sus declaraciones sobre la existencia de fincas comunales, baldias y de señorio enviadas en 1931 poco después de la proclamación de la República a petición del Gobernador; más tarde se crearia un equipo de trabajo para revisar el Catastro del Marqués de la Ensenada y se reunirian investigaciones en un cuadernillo de 67 folios manuscritos resumidos en algunas cuartillas mecanografiadas sobre cuyo contenido puede ilustrar la relativa a AYLLON:

Señor. Marquesa viuda de Villena.

Alcabalas. Ocho mil trescientos cincuenta y ocho reales.

Tercias reales. Mil nuevecientos cincuenta y siete reales.

Señorio. Sólo la regalia de nombramiento y aprobación de Justicias y Alcalde del Castillo.

\footnotetext{
${ }^{4}$ Evidentemente, el malestar campesino y las protestas contra lo que consideran abusos señoriales es anterior a la proclamación de la República, pero ésta hizo concebir nuevas esperanzas especialmente desde el momento en que, a finales de junio de 1931, se llevó a cabo una encuesta nacional, provincia por provincia y municipio por municipio, para conocer las tierras comunales, baldias y de señorio susceptibles de mejoras o de distribución entre los colonos o entre los sin tierra. La aprobación de la Ley de Reforma Agraria es la respuesta de la Administración a los escritos de los Ayuntamientos y de los particulares.
} 
Derechos de riegos. Cincuenta y cuatro reales de vellón.

Feria. Cien reales que percibe por la de San Juan... al tres por cien.

Mercados. Por la alcabalilla celebrada los jueves para grano, y en tiempo de cuaresma pescado y legumbres, dos mil setecientos noventa y cuatro reales.

Escribanias. Cuatro escribanias numerarias por las que no percibe nada, pero que producen a los titulares nueve mil setecientos reales. reales.

Oficios de procurador. Uno de causas, que produce al titular cuarenta

Derecho de portazgo y puente. Mil doscientos cincuenta reales.

Salarios. Dos mil doscientos reales al Corregidor, ciento diecisiete reales y dos maravedis al Alguacil, trescientos tres reales de tercias para las villas de dicho partido.

Censos perpetuos. Mil setecientos dieciséis reales de principal, cincuenta y un reales y dieciséis maravedis de réditos al tres por ciento, sobre un soto; ciento cincuenta reales de principal, cuatro reales y medio de réditos, sobre un solar; ciento cincuenta y siete reales de principal, cuatro reales y catorce maravedis, sobre un huerto.

Cargas perpetuas, Molino, Casas, Fincas de regadio.... 5.

Armado con este bagaje histórico, el 29 de junio de 1936 el Gobernador - siguiendo órdenes del Ministro de Agricultura- se dirigió por teléfono y telégrafo a todos los alcaldes de la provincia e hizo publicar en el Boletín de la Provincia (1 de julio) la siguiente orden:

... a los fines de aplicación inmediata de la Reforma Agraria, todos los alcaldes de esta provincia remitirán a este Gobierno Civil, en el plazo de cuarenta y ocho horas, una relación de las fincas que resulten o presuman sean de señorio, expresando su extensión, liquido imponible de cada una y nombre del propietario actual, especificando si es heredero del señor de ellas o las adquirió por compra, permuta o ejecución, y separadamente iguales datos de aquellas que aun no siéndolo en la actualidad, hayan sido de señorio, con su denominación antigua y fincas a las que actualmente pertenecen...

Las respuestas llegaron puntualmente y fueron clasificadas y colocadas en carpetas con títulos claramente expresivos de su contenido: "Con-

\footnotetext{
${ }^{5}$ Las cargas perpetuas son obligaciones de carácter religioso: 8.130 reales al convento de religiosas, 64 al convento de San Francisco, 58 a! Hospital, 12 al cabildo eclesiástico del lugar, 120 reales por réditos para la congrua de los curatos de las parroquias...

Se cita la propiedad de un molino, de una casa y de varias fincas de regadio.
} 
testaciones de los Ayuntamientos. Negativas. Habrá señorio pero sin fincas del señor jurisdiccional.-Afirmativa. Habrá señorio y fincas.-Pueblos que según el Catastro del Marqués de la Ensenada no constituyeron señorio jurisdiccional.-Relaciones completas de las fincas que son de señorio jurisdic cional (Apartado $6 .^{\circ}$ de la Base 5. ${ }^{a}$ )". En esta última carpeta se intenta relacionar los datos del Catastro con los facilitados por los Ayuntamientos. Por razones de tiempo, (las respuestas llegaron entre el 2 y el 3 de julio de 1936), la relación no llegó a terminarse pero se conservan los datos de Arcones, Ayllón, Cuéllar, Monterrubio y Perosillo.

Analizar los cientos de respuestas de 1931 y 1936 exige un tiempo y un espacio del que no disponemos y quizá convenga esperar a mejor ocasión para llevar a cabo un estudio más amplio teniendo en cuenta los datos aportados por todas y cada una de las provincias ${ }^{6}$; de momento, nos conformamos con llamar la atención sobre el interés de estos documentos, lógicamente ignorados por medievalistas y modernistas, y a estudiar con un mínimo de detalle tres casos segovianos que llegaron hasta la Dirección General del IRA: el planteado por el Ayuntamiento de Madriguera que solicita la cabolición de gravamen de origen señorial que pagan hoy los vecinos a Don Aurelio y don Leoncio González de Gregorio y Martínez de Azagra" presentado el 16 de febrero de 1935 e informado el 17 de julio de 1936; el incoado a petición del alcalde de Estebanvela que «solicita la cancelación de un censo, por creerlo de origen señorial, basándose en el Decreto de 24 de noviembre pasado»; entró la petición en el IRA el 28 de diciembre de 1933, se dictó resolución el 11 de octubre de 1934 y el 25 del mismo mes se dio el correspondiente traslado a las

\footnotetext{
${ }^{6}$ Aunque, como hemos indicado, no es el momento de analizar la documentación en profundidad, no estará de más recordar que hay una fuerte tendencia a confundir señorial con gran propiedad o con propiedad no cultivada por sus dueños. Asi se deduce, al menos, de las respuestas dadas en 1936 por los Ayuntamientos de Ciruelos de Coca, Languilla, Garcillán...

En Ciruelos se indican como señoriales 41 fincas, con una extensión total de 23 Has y 35 áreas del marqués de Cilleruelo y 39 fincas de Nicolás Martínez, compradas al conde de Torrearias, o 24 fincas del Ayuntamiento que tiene el dominio útil mientras el dominio directo corresponde al marqués de Santa Marta y conde de Torrearias, según escritura de 1501. En Languilla se habla de una finca, conocida como Renta del Concejo procedente del Vinculo y Mayorazgo de San Esteban de Gormaz fundado en la villa de Olmedo en 30 de septiembre de $1837 . .$. y en Garcillán llega a identificarse señorio con la propiedad en manos de forasteros: "Se presume no existan fincas rústicas que procedan de señorio y si únicamente los propietarios forasteros... Existen ademas otros pequeños propietarios forasteros que asi bien las tienen arrendadas en pequeñas porciones creyendo asi bien no procedan de señorio", y en Navares de Enmedio se incluye como de señorio "una finca señorial.. con varias dependencias, huerta y jardin... perteneció al ex Ministro don Vicente de Armeztom.
} 
partes. Por último, la petición de los vecinos de Vegas de Matute «que solicitan sea expropiada la finca El Carrascal y se hagan asentamientos", cursada el 26 de marzo de 1936.

\section{MADRIGUERA}

La oposición al censo "señorial» es anterior a la Reforma y se ha manifestado en diversas denuncias ante los tribunales cuyos fallos no han favorecido a los reclamantes por lo que al aprobarse la Ley de Reforma Agraria el Ayuntamiento se apresura a presentar la oportuna reclamación en fecha que ignoramos porque al publicarse el Decreto del 24 de noviembre de 1933 la instancia fue devuelta por el Director General del IRA “con la documentación que la acompañaba, con objeto de que le sirvan una y otra, para formular nuevamente la reclamación y para probar sus asertos con arreglo al Art. 5. , del mencionado Decreto".

El nuevo escrito fue presentado el 30 de agosto de $1934^{7}$ y en él se indica que «desde el siglo $x v$, los vecinos de este referido pueblo de Madriguera, hoy el Ayuntamiento, han venido pagando un censo de ochenta fanegas, trigo y cebada por mitad, y cuatro gallinas, actualmente, a don Aurelio y don Leoncio González de Gregorio y Martínez de Azagra, sin conocer el objeto o cosa sobre que grava el mismo». Tras la exposición central se hace una breve historia desde el año 1920: a la pregunta de los vecinos del porqué de tal pago respondieron los beneficiarios con una demanda de juicio de mayor cuantia en el que se condenó al Ayuntamiento al pago y "a autorizar escritura de reconocimiento del mismo" con hipoteca sobre los bienes comunales como garantia del pago. Al aprobarse la Ley de Reforma, el Ayuntamiento se considera libre de sus obligaciones y pide la oportuna declaración para lo que acompaña en debida forma los documentos pertinentes ${ }^{8}$.

De acuerdo con las normas del Decreto, y con otros seis meses de retraso, el Instituto de Reforma Agraria dio traslado del escrito a los be-

\footnotetext{
La instancia primitiva fue devuelta el 14 de diciembre de 1933 y la Corporación municipal acordó acogerse al nuevo decreto el 24 del mismo mes, pero no lo hizo hasta ocho meses más tarde y a través del «Regidor primero del Ayuntamiento... en funciones de Alcalde del mismo por enfermedad justificada del titular...". El retraso y la ausencia del Alcalde quizá se deban a la resistencia de éste a plantear un caso ya fallado negativamente por los tribunales.

- Copia de la sentencia de la Audiencia Territorial de Madrid, copia del apuntamiento formado por la misma, copia del recurso de casación interpuesto por el Ayuntamiento, copia de la sentencia del Tribunal Supremo, copia de la nuta formada para dicho recurso y, por último, testimonio de un curioso documento presentado por los beneficiarios del censo, sobre el que volveremos más adelante.
} 
neficiarios y les fijó plazo para responder y aportar las pruebas que consideraran pertinentes. El 16 de abril de 1935 entró en el Servicio Juridico del Instituto el escrito firmado por el procurador Eduardo Morales Diaz en nombre de Aurelio y Leoncio González ${ }^{9}$, oponiéndose a la petición de Madriguera con argumentos extraidos de los mismos documentos alegados por el Ayuntamiento y de "las contestaciones a las preguntas segunda, vigésima sexta y vigésima octava..." del Catastro del Marqués de la Ensenada ${ }^{10}$.

Finalmente, el 17 de julio de 1936, el Jefe del Servicio Juridico elevaba informe al Director General del Instituto en el sentido de:

1. Q Que procede declarar abolida sin derecho a indemnización la renta de ochenta fanegas... por resultar prestación señorial conforme a los n. $.^{\circ} 3 .^{\circ}$ y $4 .^{\circ}$ del Decreto de 24 de noviembre de 1933 en relación con la base 22 de la Ley de 15 de septiembre de 1932.

2.․ Que por el Registrador de la Propiedad de Riaza se cancelen todos los asientos que en aquel Registro se refieren a dicho gravamen, asi como las menciones del mismo en otros asientos ".

El informe del Servicio Jurídico se basa en la Ley de Reforma y en el Decreto que la desarrolla, y tiene en cuenta las noticias y pruebas históricas aportadas por unos y otros, que coinciden en dar por sentado el origen del censo en el siglo $x \mathrm{v}^{12}$, aunque la primera referencia digna de crédito es del año 1574, fecha en la que el Concejo y vecinos de Madriguera reconocieron que "deben y pagan a los Señores Francisco Arias de Herrera y Doña Leonor de Verástegui, su mujer... 80 fanegas... de censo e tributo enfitéutico perpetuo e a un apeo antiguo que dicho Sr. Francisco Arias de Herrera tiene sobre que está cargado e fundado dicho Censo".

${ }^{9}$ Se incluye el poder dado al procurador.

${ }^{10}$ El recurso al Catastro está generalizado en todas las provincias, pero en algunas como León los municipios no se conforman con copias debidamente garantizadas, como la presentada en Segovia, sino que aportan el volumen correspondiente, que todavia hoy puede ser consultado en los fondos del IRYDA.

$"$ El expediente nunca fue cerrado ni hay costancia de que se comunicara acuerdo alguno a los interesados por lo que cabe suponer, lógicamente, que los sucesos del 18 de julio hicieron olvidar los pequeños problemas señoriales arrastrados durante siglos.

12 La fijación en el siglo xv procede de una declaración hecha en juicio por los beneficiarios en 1644: venian percibiendo el censo ellos personalmente desde hacia más de cincuenta años «e ansi mismo lo habian pagado de más de cien años a esta parte a Pedro Núñez de Guzmán su padre e a los demás sus antecesores". 
Este primer documento asi como el apeo al que alude son citados en una Carta Ejecutoria de la Real Chancilleria de Valladolid ${ }^{13}$ que tampoco conocemos por haberse presentado como prueba ante los jueces en el pleito entablado contra el Concejo en 1920. Constituido en el siglo xv o en el XVI, no parece haber dudas sobre su pago durante años hasta que en 1644 los Regidores del lugar indicaron que «querian saber en virtud de qué, porque hasta ahora lo habían venido pagando con ignorancia». El pleito iniciado por la negativa de los regidores al pago del censo finalizó en 1647 con la condena al pago de las fanegas de grano y de las gallinas.

Empeñado en probar que el censo es señorial por cuanto no se relaciona con fincas o propiedades concretas, el Concejo interpreta en este sentido el reconocimiento de censo hecho el 23 de junio de 1744 a favor de José de Medrano: como éste no poseia bienes que pudieran justificar el censo, se vio obligado a tomar posesión en la fuente pública ${ }^{14}$. El documento, conservado gracias a una copia, con numerosos errores, de 1933, merece ser reproducido en su parte esencial que recoge la toma de posesión hecha al heredar estos derechos Lorenzo de Medrano:

...en el año pasado de mil setezientos quarenta y quatro... se halla un pedimiento presentado por don Joseph Medrano, becino de la villa de Almazán como apoderado de Dn Lorenzo Medrano y Guzmán, señor de la villa de Cabanillas su padre y señor en que pide... la posesión en el lugar de Madriguera y Francos... Dicho dia, yo el sobredicho Manuel Nonua, notario, escribano del número y ayuntamiento de la villa de Aillón, su tierra y del estado de Cavalleros Fijos dalgo de ella, en cumplimiento de mi comisión pasé a el lugar de Madriguera de esta qn (ijurisdicción?) y haviendo llegado al fuente de que se alla por bajo de dicho lugar caminando azia el lugar del Negredo de dicha qn, que es de piedra con su arco por encima, donde habia diferentes mozas para coger agua y acompañándome el referido Dn. Joseph Medrano... y testigos que se allaron presentes, le tomé por la mano y llegué a la dicha fuente como

\footnotetext{
${ }^{13}$ El apeo lleva la fecha de 1504. Los beneficiarios del censo afirman que fue realizado para garantizar el cobro y hablan de «un apeo de todas las fincas del lugar» mientras quienes se oponen al pago recuerdan que el apeo no tiene nada que ver con el censo: "se solicitó en 4 de octubre de 1.504 por Francisco de Hermosa, en nombre y representación de la muger e hijos de Juan de Coritreras, que teniendo en la Villa y lugar de Madriguera diferentes bienes, se hiciera el correspondiente apeo, y acordado asi por éste, y dados los pregones legales, el dia 3 de diciembre de 1504, al apeo de las fincas deslindadas en la referida escritura».

Posiblemente se conserven estos documentos asi como el pleito de 1644-1647 entre los fondos de la Chancilleria.

ia Lógicamente, la parte contraria utiliza el mismo texto para probar el cobro pacífico del censo.
} 
hipoteca especial del ynfiteusis que les aga el conzejo y vecinos de dicho lugar de Madriguera de ochenta fanegas de pan por mitad trigo y zebada en cada un año y quatro gallinas y dos jarras de agua ${ }^{15}$, y en voz y en nombre de los demás bienes afectos al dicho tributo y mayorazgo fundado por Dn Juan de Guzmán y Quiñones... y le di la posesión Real actual corporal, Belquasi, del dicho vinculo en la dicha fuente en boz y nombre de los demás bienes del dicho vinculo, y en señal de posesión sacó agua en un jarro, bebió de ella, impidió la tomasen las dichas mozas que habian acudido por ella y después les dio lizencia para que tomasen agua de dicha fuente e hizo otros actos de posesión y de que la tomaba quieta y pacificamente y sin contradición alguna, lo pidió por testimonio y según lo mandado estoy pronto a darle cada que me sea pedido y notifiqué a Francisco Muñoz, vecino y Regidor de dicho lugar le acudiese con las rentas actuales...

Para no ser menos, también los beneficiarios presentarán como prueba un nuevo documento no utilizado en los pleitos anteriores, que no es sino la certificación del Catastro del Marqués de la Ensenada que prueba que Madriguera pertenecía al señorio del marqués de Villena o, dicho de otro modo, que el censo y el señorio nada tenian que ver pues mientras el señor era el marqués, cobraba el censo José Medrano:

A la segunda, que es de señorio sugeto a la jurisdición de la Villa de Ayllón con los demás pueblos de su comprehensión pertenece a el Escelentísimo Señor Marqués de Villena y le contribuyen con el derecho de alcavalas... y a su magestad con las demás contribuciones generalmente establecidas...

A la veinte y seis: que tiene por carga de justicia dos censos perpetuos, el uno a favor de Dn. Joseph Medrano vecino de la villa de Medinaceli, por el que anualmente satisfazen ochenta fanegas..., y el otro a favor de la cofradia del Santisimo de la Parroquial de este lugar...

Tras considerar los pros y contras, el responsable del Servicio Jurídico decidió que al censo de Madriguera le era aplicable el artículo $3 .^{\circ}$ del Decreto en sus presunciones $3 .^{a}$ y $4 .^{a}$ que dicen que se presumirá señorial la prestación «cuando los pagadores sean pueblos y el reparto de la prestación se haga entre sus vecinos y cuando no recaigan sobre fincas especificamente determinadas" ya que como recoge el preámbulo del Decreto «no cabe reputar la prestación como carga real, sino como una capitación cuya inclusión entre las prestaciones de origen señorial

Olvidadas por todos, quizá por su nulo valor económico aunque sea éste precisamente el que le da interés político. 
resulta indiscutible añadiendo que es evidente que en todos estos casos no se trata de derechos reales legitimos, sino de tributos propios de la época en que los poseedores de los señorios trataron, consiguiéndolo en la inmensa mayoria de los casos, de confundir el feudo con otras instituciones distintas, trasladando los tributos del hombre a la tierra, pero dejando sujetos en definitiva, al hombre y a la tierra" ${ }^{16}$.

\section{ESTEBANVELA}

Mejor documentado desde el punto de vista cronológico es el censo que gravaba, desde 1484, el Coto Redondo de Estebanvela denominado la «Divisa o Santísima Trinidad» según noticia recogida en la copia de un documento de 1563 por el que se redimió una parte del censo (pasó de ciento cinco fanegas de trigo y centeno y cuatro pares de gallinas a cincuenta fanegas más las gallinas) pagando por ella la cantidad de cuatrocientos ochenta mil maravedis que, explican los vecinos, equivalen a treinta y siete mil quinientas pesetas de la época.

El Concejo reconoció en diversas ocasiones la validez del censo, que pasó por diversas manos hasta llegar a las del beneficiario Leoncio Sanz Martin al que dejó de pagarse en 1933 al entrar en vigor la Ley de Reforma Agraria "cuya Base 22 considera de suma necesidad e injusta la continuidad de estas cargas", según declara el Concejo en instancia dirigida al IRA el 20 de diciembre de 1933. En este caso el Instituto actuó con rapidez y el 17 de enero se enviaba copia al beneficiario, que presentó sus alegaciones el 12 de marzo de 1934. El 9 de octubre del mismo año, el Servicio Juridico informaba negativamente la petición del Concejo y dos dias más tarde el Consejo Ejecutivo hacia suyo el informe por haberse probado:

... que la prestación proviene originariamente de un censo enfitéutico acordado entre personas libres mediante un contrato civil perfectamente

\footnotetext{
${ }^{16}$ Eritre las alegaciones de las partes se citan resoluciones como la de la Dirección General de los Registros del 13 de enero de 1900 por la que se declaran enfitéuticos todos los censos del siglo xv: "los censos constituidos en 1431 no pudieron ser sino enfitéuticos pues de esta y no de otra clase eran los nacidos en aquella época de reconquista y de repoblación en que las tierras estaban infecundas e incultas, pues es sabido que la enfiteusis era el contrato de entonces asi como el consignativo y el reservativo lo fueron más tarde cuando las tierras eran ya productivas para el cultivo y cuando con el descubrimiento de América se produjo gran aumento de dinero, mucho del cual se consignó en tributo sobre las tierras productivas...". Ésta y otras resoluciones y fallos de los tribunales, que recurren una y otra vez a las Partidas como texto legal, son un punto de partida inapreciable para quien desee averiguar el concepto que de la Edad Media se tenia en el siglo xix y en los años iniciales del $x x$.
} 
sin relación alguna con derechos señoriales...; no aparece probado por don Juan Ramírez de Morales, vecino del lugar de Prádena, aldea de la villa de Sepúlveda que constituyó el censo de referencia en 1484 fuese el señor de Estebanvela como de haberlo sido se desprenderia de las formas usuales en la época al constituir los señores gravámenes o derechos reales en sus villas y lugares...

En este caso, la base para negar la supresión del censo son los documentos históricos presentados por los reclamantes, a los que se da capacidad probatoria "aunque no se hallan expedidas (las escrituras) por funcionarios competentes" sino por el Secretario del Ayuntamiento que reproduce una certificación de la Audiencia Territorial de Valladolid, de 1883, referente a los antecedentes presentados por Estebanvela en un pleito con el lugar de Villacorta por la posesión de la Divisa o Santisima Trinidad. Entre los antecedentes a los que se hace mención figuran y se reproducen documentos de 30 de marzo de 1602 y 25 de septiembre de 1715 en los que se alude repetidamente al escrito de 1484 que, al parecer, estaba incluido en otro documento del 26 de agosto de 1617 del que el Ayuntamiento no dispone de copia uni conoce el archivo en que pueda encontrarse la escritura", que sabemos perdida en 1602 y encontrada antes de 1715, según se deduce, confusamente, del testimonio "de Marcos Sánchez, Escribano que fue de la Villa de Ayllón de que aparece un traslado signado según han comprendido de Juan de de San Ramón, Escribano que también fue en ella, el cual se halla inserto para mayor seguridad en un reconocimiento que celebró el dicho Concejo por testimonio de Juan de Maderuelo, también escribano, difunto, de la dicha Villa en los veintiséis de agosto del año pasado de mil seiscientos y doce...".

Cuanto hoy podemos saber es que el mencionado tributo fue fundado por Juan Garcia, caballero, Gil Garcia, Martín Sánchez y otros vecinos por voz de Concejo en favor de Juan Ramirez de Morales, suponiendo que realmente existiera el documento de 1484 pues lo único probado es que en 1602, el Concejo y hombres buenos de Estebanvela reconocen que desde tiempo inmemorial se pagaba censo perpetuo "en favor de una capellania perpetua que Diego de Anaya, difunto, vecino que fue de la dicha villa de Ayllón, dejó fundada e instituida en el Monasterio de San Francisco... de ciento e cinco fanegas de trigo e centeno por mitad, e cuatro gallinas vivas y otras cosas en cada un año... y... el Concejo compró e redimió las cincuenta e cinco fanegas de trigo e centeno... de Francisco de Temiño e Gerónima de Meneses... señores de ello... como se declara y contiene en la venta e redención... fecha a veinte e tres de octubre de mil y quinientos e sesenta y tres años...". 
El reconocimiento de 1602 incluye una serie de condiciones que tiene algún interés conocer: el grano se entregaria el dia de San Miguel de cada año, «con buena medida, ora seco y enjuto de dar e de tomar puesto y encamarado en una de las cámaras que dicho Concejo señalase", y las gallinas, buenas, atadas y situadas en el lugar de Estebanvela donde, junto con el trigo, serian recogidas a costa de la capellania; si ésta no retirara el grano antes de Navidad, deberia pagar el "camaraje». Cada diez años se haría un nuevo reconocimiento del censo aunque si se omitiera no por ello prescribiria la obligación cuyo pago se garantiza con los bienes del Concejo de los «que sea visto nosotros e nuestros subcesores ser inquilinos poseedores de los propios del dicho nuestro Concejo en nombre del tal Capellán y patrón y por tales nos tenemos e nombramos", confesión que, sin duda, influyó en la decisión tomada por el Instituto de Reforma Agraria para mantener el censo en vigor ${ }^{17}$.

\section{VEGAS DE MATUTE}

En principio, los vecinos de Vegas no piden la supresión de censos señoriales sino la expropiación y parcelación de la finca «El Carrascal» que ocupa más de la mitad del término municipal y es improductiva por dedicarla su dueña, la excondesa de Cifuentes y viuda del Conde de Girardeli a la caza, que ha proliferado hasta destrozar los cultivos de los particulares situados en sus cercanias. Los labradores reaccionaron en 1918 asaltando la finca y destrozando la caza y aunque fueron rechazados por la fuerza pública, el riesgo de nuevas alteraciones obligó al Gobernador a buscar un acuerdo (se acompaña una copia) por el que el Conde se obligaba a «descastar sin interrupción y por todos los medios humanos posibles los Conejos que existan en sus fincas enclavadas en el Carrascal». El acuerdo fue incumplido y los vecinos decidieron, en 1932, pedir la expropiación de la finca por ser de «señorio trasmitido a la actual dueña por herencia directa como se justifica con la certificación de la Escritura de reconocimiento de Señorio y Vasallaje a fabor de los antecesores de esta repetida Señora de fecha 5 de enero de 1707 por lo cual está

"Evidentemente, las pruebas documentales aportadas no eran suficientes y de ello estaba convencido el beneficiario del censo que acusa al Concejo de "inocente" pues mientras no se halle la escritura de fundación las deducciones del Ayuntamiento «no dejan de ser una quimera o el producto de una imaginación calenturienta". Dispuesto a colaborar, Inocencio Sanz declara haber realizado investigaciones en todos los archivos "en que pudiera existir algún dato fehaciente que acreditara el carácter señorial del expresado censo, sin haberlo conseguido" y estimula a la Dirección del IRA, "que tantos medios cuenta para ello se sirva realizar gestiones o pedir pruebas que de una manera categórica demuestren la procedencia del censo para resolver en justicia". 
comprendida en el apartado sexto de la Base quinta de la Ley de Reforma Agraria y debe ser expropiada preferentemente sin indemnización como marca dicha Ley".

Ni esta petición ni el intento de incluir la finca en el Inventario de Fincas Expropiables, en 1933, sirvieron de nada y la tensión social no hace sino agravarse, motivo por el cual se eleva el escrito con más de cien firmas, escrito que tampoco serviria de mucho pues en mayo de 1936 se les contestó que si bien el documento de 1707 reconocia el señorio de Micaela de Vargas, "por ella no aparece probado que la finca objeto de la solicitud hubiera pertenecido a dicha señora o a los titulares de dicho señorio" y sería necesario presentar ante el Instituto "documentos que prueben que dichos terrenos pertenecieron y siguen perteneciendo a los poseedores de dichos títulos asi como que a estos correspondió antes de la abolición de los señorios, el jurisdiccional del término de Vegas del Matute, según los antecedentes que obren en el Archivo Municipal del pueblo". Si tales documentos existieron y fueron enviados al instituto, hasta nosotros no han llegado.

Si se conserva, en cambio, copia de la escritura de 1707 en la que se aprueba y ratifica la posesión que los vecinos de Vegas dieron el 27 de enero de 1606 «del Señorio y Vassallaje... a dicha Excma. Sra. Doña Michaela Ybáñez de Segovia, marquesa de Gramosa, vizcondesa de esta Villa, su Señora... Los términos del reconocimiento son los siguientes:

Que dichos Señores... por si y en nombre de esta Villa... reconocen, tienen y reciben con toda veneración y rendimiento por su legitima Señora a la Excelentísima Señora... debaxo de cuya protección y amparo se ponen y constituyen por sus Vasallos por el mencionado Señorio y Vasallaje que tiene de esta Villa con obligación que tienen de guardar y observar todos los decretos, órdenes y preceptos y mandatos que les pusiere, diere y expediere obedeciéndolos con pronta execución como también las eleciones de Justicias, que de los que se propusiesen por los Jurados que fuesen, gustase su Excelencia elexir y hacer cada año; y de recibir como lo tienen hecho al Alcalde mayor a quien tiene nombrado y nombrase: uno y otro por el tiempo que fuese voluntad de su Excelencia y de quien su derecho hubiere, y que acudirán a sus llamamientos y en todo obedecieran lo que los mandase debaxo de las penas y apercibimientos que les impusiere, las cuales quieren y consienten se executen en las personas y bienes a quien toquen, celando y velando en su execución que harán con los demás que sea del servicio de Dios nuestro Señor el de su voluntad de Majestad de su Excelencia y utilidad desta Villa su quietud y buena administración de Justicia para que dicha Excelentisima Señora y quier su derecho hubiere ha de poder usar de todos los derechos, aciones y señorios que le pertenezcan y pueda co- 
rresponder conforme ha dicho y dispuesto por leyes de estos Reinos por el Señorio y Vasallaje que como ha referido tiene de esta Villa arreglándose a lo capitulado y expresado en las escrituras con que se vendieron y de que tomó la posesión dicho Señor don Pedro Ybáñez de Segovia Padre de su Excelencia...

Los documentos citados son sólo una muestra de los cientos o miles que aparecerán el dia en que se estudien los fondos de la Reforma Agraria, que permitirán conocer mejor nuestra Historia Contemporánea y, también, como deciamos al comienzo de este articulo, nuestra Historia Medieval y Moderna. Baste por el momento llamar la atención sobre su existencia y sobre la riqueza de los archivos custodiados por el IRYDA al que agradecemos las facilidades dadas para la consulta de estos fondos. 